\title{
Kinerja Katalis Ni-Cu/HZSM-5 dalam Pembuatan Biogasoil dari Minyak Bintaro (Cerbera Manghas) dengan Proses Hydrocracking
}

\author{
(Performance oF Ni-Cu/HZSM-5 Catalyst in Hydrocracking Process to Produce \\ Biogasoil from Cerbera Manghas Oil)
}

\author{
Afrida Nur Aini ${ }^{* *}$, Muhammad Al-Muttaqii ${ }^{2}$, Achmad Roesyadi ${ }^{1}$, Firman Kurniawansyah ${ }^{1}$ \\ ${ }^{1}$ Departemen Teknik Kimia, Fakultas Teknologi Industri dan Rekayasa Sistem, \\ Institut Teknologi Sepuluh Nopember \\ Jl. Teknik Kimia, Sukolilo, Surabaya 60111 \\ ${ }^{2}$ Balai Penelitian Teknologi Mineral, Lembaga Ilmu Pengetahuan Indonesia \\ Jl. Ir. Sutami Km.15, Tanjung Bintang, Lampung Selatan 35361 \\ ${ }^{*}$ Penulis Korespondensi E-mail: afrida.ad@gmail.com
}

\begin{abstract}
Abstrak
Catalytic cracking dan hydroprocessing merupakan dua proses yang digunakan untuk mengubah minyak nabati menjadi biofuel, gabungan dari kedua proses tersebut dinamakan reaksi hydrocracking. Minyak bintaro yang bersifat non-edibleoil serta memiliki kadar minyak cukup banyak yakni sebesar 35-50\% dapat direkomendasikan sebagai salah satu sumber minyak nabati yang dapat diolah menjadi biogasoil. Penambahan logam nikel (Ni) dan tembaga $(\mathrm{Cu})$ ialah untuk memperoleh yield yang lebih baik daripada menggunakan satu jenis katalis. Preparasi katalis dilakukan dengan menggunakan metode incipient wetness impregnation. Variabel loading support HZSM-5 yang digunakan sebesar 5\% dan $10 \%$, serta ratio logam Ni-Cu yaitu 1:1. Katalis Ni-Cu/HZSM-5 dianalisa menggunakan BET, EDX, dan XRD untuk mengetahui karakteristik katalis. Selanjutnya proses hydrocracking dilakukan dengan mencampurkan 2 gram katalis NiCu/HZSM-5 dan $250 \mathrm{ml}$ minyak bintaro ke dalam reaktor batch berpengaduk pada suhu reaksi $375^{\circ} \mathrm{C}$ selama 2 jam. Produk cair (biofuel) yang dihasilkan dari proses hydrocracking dianalisa menggunakan GC-MS untuk mengetahui komposisi hidrokarbon. Rute reaksi yang mendominasi dalam penelitian ini ialah reaksi dekarbinolasi dan dekarboksilasi. Hal itu terlihat dari komposisi hidrokarbon terbanyak dari produk biogsoil yang dihasilkan ialah C15 dan C17. Hasil dari penelitian diperoleh $\mathrm{Ni}-\mathrm{Cu} / \mathrm{HZSM}-5$ dengan loading 5\% dan ratio logam 1:1 optimum digunakan pada proses hydrocracking minyak bintaro untuk menghasilkan biogasoil dengan yield sebesar 82,7\%.
\end{abstract}

Kata Kunci: hydrocracking, minyak bintaro, Ni-Cu/HZSM-5, dan biogasoil.

\section{Abstract}

Catalytic cracking and hydroprocessing are two processes used to convert vegetable oils into biofuels, a combination of the two processes is called a hydrocracking reaction. Bintaro oil which is non-edibleoil and has a high oil content of 35-50\% can be recommended as a source of vegetable oil that can be processed into biogasoil. The addition of nickel (Ni) and copper (Cu) is to obtain a better yield than using one type of catalyst. The catalyst preparation was carried out using the incipient wetness impregnation method. The loading support variable HZSM-5 used is 5\% and 10\%, and the Ni-Cu metal ratio is 1: 1. Ni-Cu / HZSM-5 catalysts were analyzed using BET, EDX, and XRD to determine the catalyst characteristics. The hydrocracking process is then carried out by mixing 2 grams of Ni-Cu / HZSM-5 catalyst and 250 ml of bintaro oil into a stirred batch reactor at a reaction temperature of $375^{\circ} \mathrm{C}$ for 2 hours. The biofuel produced from the hydrocracking process is analyzed using GC-MS to determine the hydrocarbon composition. The reaction route that dominates in this study is the decarbinolation and decarboxylation reaction. This can be seen from the composition of the most hydrocarbons from the biogsoil product produced is C15 and C17. The results of the study obtained Ni-Cu / HZSM-5 with a loading of 5\% and optimum metal 1: 1 ratio used in the hydrocracking process of Bintaro oil to produce biogasoil with a yield of $82.7 \%$.

Keywords: hydrocracking, bintaro oil, Ni-Cu/HZSM-5, and biogasoil.

\section{PENDAHULUAN}

Penggunaan minyak fosil secara terus menerus menimbulkan dampat negatif terhadap lingkungan seperti percepatan pemanasan global (the accelerate of global warming), emisi gas $\mathrm{CO}_{2}$, efek rumah kaca, polusi udara dan masalah-masalah lingkungan lainnya. Di sisi lain kebutuhan terhadap minyak bumi terus mengalami peningkatan sejalan dengan pertumbuhan penduduk di Indonesia. Menurut Kementerian Energi dan Sumber Daya
Mineral(ESDM), produksi minyak mentah di Indonesia dari tahun 2012 hingga 2017 terus mengalami penurunan. Produksi minyak mentah di tahun 2012 mencapai 859.743BOPD sedangkan pada tahun 2017 produksi minyak mentah hanya mencapai 801.024 BOPD. Apabila konsumsi bahan bakar minyak bumi di Indonesia tidak berubah dan tidak adanya upaya suatu alternatif baru, maka diperkirakan cadangan minyak bumi di Indonesia akan habis dalam 12 tahun mendatang [1]. 
Salah satu upaya yang dilakukan pemerintah untuk mengatasi krisis energi yaitu mengembangkan sumber daya terbarukan. Melalui Instruksi Presiden No. 1/2006 tentang penyediaan dan pemanfaatan bahan bakar nabati (biofuel) sebagai bahan bakar lain, merupakan suatu instruksi yang menegaskan pentingnya pengembangan Bahan Bakar Nabati [2].

Sumber biomassa yang berpotensi sebagai bahan bakar nabati ialah bintaro (Cerbera Manghas). Buah bintaro terdiri atas $8 \%$ biji dan $92 \%$ dagingbuah. Bijinya sendiri terbagi dalam cangkang $14 \%$ dan daging biji $86 \%$. Biji bintaro mengandung minyak antara $35-50 \%$ [3]. Bila seluruh kebutuhan biofuel disuplai dari bintaro, akan dibutuhkan biodiesel sebanyak 720.000 kiloliter atau setaradengan 5,1 juta ton biji bintaro, dengan asumsi bahwa $2,5 \mathrm{~kg}$ biji bintaro akanmenghasilkan 1 liter minyak bintaro [4].

Hydrocracking merupakan salah satu metode yang dapat mengkonversi minyak nabati menjadi biofuel melalui proses pemecahan molekul hydrocarbon dengan menggunakanpanas, katalisator, dan adanya penambahan gas hidrogen [5]. Penambahan gas hidrogen dapat membantu menghilangkan atomoksigen dan membentuk $\mathrm{H}_{2} \mathrm{O}$, CO, dan $\mathrm{CO}_{2}$; serta mampu meminimalkan pembentukan coke sehinggamemperlambat deaktivasi katalis oleh pore blockage [7].

Trigliserida yang terdapat pada minyak bintaro mulamula dikonversi menjadi paraffin atau hydrokarbon alkana, kemudian mengalami proses berturut-turut yaitu decarboxylation, decarbonylation, dan hydrodeoxygenation [6]. Adapun uraian lengkap reaksi hydrocracking adalah sebagai berikut:

a. Reaksi dekarboksilasi, pada reaksi ini terjadi pembentukan $\mathrm{CO}_{2}$

$$
\mathrm{C}_{17} \mathrm{H}_{35} \mathrm{COOH}->\mathrm{C}_{17} \mathrm{H}_{36}+\mathrm{CO}_{2}
$$

b. Reaksi dekarbonilasi, reaksi ini menghasilkan hidrokarbon utama dengan bilangan karbon ganjil dengan byproduct $\mathrm{H}_{2} \mathrm{O}$ dan $\mathrm{CO}$.

$$
\mathrm{C}_{17} \mathrm{H}_{35} \mathrm{COOH}+\mathrm{H}_{2}->\mathrm{C}_{17} \mathrm{H}_{36}+\mathrm{H}_{2} \mathrm{O}+\mathrm{CO}
$$

c. Reaksi hidrodeoksigenasi (reduksi), reaksi ini menghasilkan hidrokarbon utama dengan bilangan karbon genap dengan byproduct $\mathrm{H}_{2} \mathrm{O}$

$$
\mathrm{C}_{17} \mathrm{H}_{35} \mathrm{COOH}+3 \mathrm{H}_{2}->\mathrm{C}_{18} \mathrm{H}_{38}+2 \mathrm{H}_{2} \mathrm{O}
$$

Penggunaan zeolite HZSM-5 yang mempunyai strong acidity telah diaplikasi pada beberapa studi tentang proses hydrocracking dan hydroisomerization minyak nabati menjadi gasoline range hydrocarbons [7]. Namun, katalis ini memiliki kelemahan yaitu masih rendahnya yield fraksi liquid yang dihasilkan serta mudahnya katalis terdeaktivasi. Zeolit HZSM-5 ini mempunyai pori ukuran mikro $(<2 \mathrm{~nm})$ sehingga dapat menyebabkan polimerasi by-product atau reaction intermediates yang menutupi inti aktif katalis (active sites) di dalam saluran mikropori [20]. Hal tersebut mengakibatkan laju difusi berlangsung lambat.

Oleh karena itu, penelitian ini mengkombinasi logam transisi $\mathrm{Ni}$ dan $\mathrm{Cu}$ (dengan beberapa variabel rasio logam) untuk meningkatkan aktivitas dari support zeolit HZSM-5. Penambahan fungsi asam pada katalis dikarenakan reaksi isomerisasi yang terbentuk dapat meningkatkan produk dengan rantai bercabang sehingga dapat memperbaiki stabilitas produk (gasoil) pada suhu rendah [8].

\section{METODE PENELITIAN}

\section{Bahan}

Bahan baku yang digunakan adalah biji bintaro yang telah dipress menjadi minyak bintaro; $\mathrm{NH}_{4}$-ZSM-5 (CAS No. 1318-02-1) denganrasio $\mathrm{SiO}_{2} / \mathrm{Al}_{2} \mathrm{O}_{3}=40$ yang diperoleh dari Zeolyst International (CBV 8014) yang kemudian dikalsinasi untuk menjadi HZSM-5; logam Ni( $\left.\mathrm{NO}_{3}\right)_{2} \cdot 6 \mathrm{H}_{2} \mathrm{O}$ dan $\mathrm{Cu}\left(\mathrm{NO}_{3}\right)_{2} .3 \mathrm{H}_{2} \mathrm{O}$ Merck.

\section{Metode}

Melakukan preparasi katalis menggunakan metode incipient wetness impregnation [9][10][11]. Impregnasi zeolit HZSM-5 dilakukan dengan menambahkan larutan garam $\mathrm{Ni}\left(\mathrm{NO}_{3}\right)_{2} \cdot 6 \mathrm{H}_{2} \mathrm{O}$ dengan rasio logam(1:1)pada support HZSM-5 dengan variabel loading (5\%, 10\%). Selanjutnya impregnasi dilakukan bertahap dengan garam prekursor $\mathrm{Cu}\left(\mathrm{NO}_{3}\right)_{2} .3 \mathrm{H}_{2} \mathrm{O}$. Lalu katalis disimpan semalaman di dalam desikator. Kemudian dikeringkan di dalam oven pada temperatur $120 \mathrm{C}$ selama 12 jam. Kemudian dikalsinasi dengan udara pada temperatur 500C selama 3 jam dandilanjutkan dengan proses reduksi dengan gas $\mathrm{H}_{2}$ pada temperatur 550C selama 2 jam.

Katalis dilakukan uji karakterisasi dengan metode Brunauer Emmett Teller (BET) untuk mendapatkan nilailuas permukaan dan volume pori katalis, X-Ray Diffraction (XRD) untuk mengetahuibentuk kristalinitas katalis dan unsur-unsur yang terdapat pada katalis, dananalisa Energy Dispersive X-ray Spectroscopy (EDX) untuk melihat kandungan logam pada katalis.

Langkah selanjutnya yaitu proses hydrocracking, dimana mencampurkan 2 gram katalis Ni-Cu/HZSM-5 dan $250 \mathrm{ml}$ minyak bintaro ke dalam reaktor batch berpengaduk. Gambar 1 menunjukkan seperangkat peralatan proses hydrocracking yang terdiri dari: 1) Tabung gas $\mathrm{N}_{2}, 2$ ) Tabung gas $\mathrm{H}_{2}, 3$ ) Valve tube gas $\mathrm{N}_{2}$, 4)Valve tube gas $\mathrm{H}_{2}$, 5) Tube reaktor gas $\mathrm{N}_{2} / \mathrm{H}_{2}, 6$ ) Indikator tekanan reaktor, 7)Thermocouple, 8) Furnace, 9) Pengaduk, 10) Reaktor, 11) Valve tube sampling cairan, 12) Pengatur kecepatan pengaduk, 13) Panel kontrol heater reaktor. Model reaktor batch yaitu Model 4563 Parr Instrument Company dengan volume $600 \mathrm{~mL}$. Kondisi operasi yang digunakan ialah $375 \mathrm{C}$, initial tekanan 11 bar, dan waktu reaksi 120 menit (2 jam). Hasil dari hydrocracking dianalisa menggunakan GC-MS untuk mengetahui rantai hidrokarbon yang terbentuk.

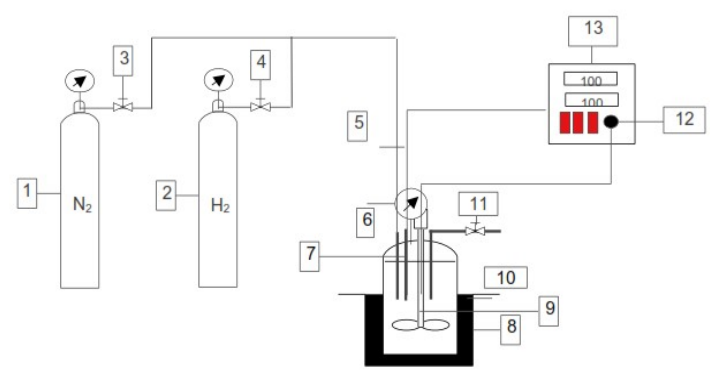

Gambar 1. Reaktor hydrocracking [3]. 


\section{HASIL DAN PEMBAHASAN}

\section{Karakteristik katalis}

Gambar 2 menunjukkan difraktogram katalis $\mathrm{Ni}-\mathrm{Cu} / \mathrm{HZSM}-5$ dengan berbagai variasi rasiodan loading logam $\mathrm{Ni} / \mathrm{Cu}$. Pada tipe katalis Ni-Cu/HZSM-5, keberadaan partikel $\mathrm{Cu}$ terlihat pada sudut $2 \theta=45^{\circ}$ dan $45,55^{\circ}$, hal ini sesuai dengan data file JCPDS No. 00-004-0850, sedangkan keberadaan partikel Ni terlihat pada sudut $2 \theta=44,5^{\circ}$, sesuai dengan data data ICDD:00-004-0850. Keberadaan logam
$\mathrm{Ni}$ dan $\mathrm{Cu}$ di dalam katalis tidak mengubah strukur kristal dari zeolite HZSM-5, namun hanya mengurangi intensitas masing-masing peak difraksi [12].

Tabel 1 menunjukkan sifat katalis Ni-Cu/HZSM-5. Setelah dilakukan proses impregnasi logam $\mathrm{Ni}$ dan $\mathrm{Cu}$ pada support HZSM-5, luas permukaan dan diameter pori dari katalis Ni-Cu/HZSM-5 yang dihasilkan mengalami penurunan. Katalis HZSM-5 yang mempunyai luas permukaan $407.386 \mathrm{~m}^{2} / \mathrm{g}$ [3] mengalami penurunan sekitar $15 \%$ setelah proses impregnasi dengan bimetal $\mathrm{Ni}-\mathrm{Cu}$.

Tabel 1. Hasil Analisa Katalis Ni-Cu/HZSM-5

\begin{tabular}{lccccc}
\hline \multirow{2}{*}{ Katalis } & \multirow{2}{*}{$\begin{array}{c}\text { Surface area }^{\mathrm{a}}, \\
\mathrm{S}\left(\mathrm{m}^{2} / \mathrm{g}\right)\end{array}$} & $\begin{array}{c}\text { Diameter pori rata-rata }^{\mathrm{b}}, \\
\mathrm{D}(\mathrm{nm})\end{array}$ & $\begin{array}{c}\text { Volume pori total }^{\mathrm{c}}, \\
\mathrm{V}\left(\mathrm{cm}^{3} / \mathrm{g}\right)\end{array}$ & \multicolumn{2}{c}{ Kadar logam d, wt.\% } \\
\cline { 5 - 6 } HZSM-5 & 407,386 & 3,120 & 0,3177 & $\mathrm{Ni}$ & $\mathrm{Cu}$ \\
Ni-Cu/HZSM-5_5(1:1) & 336,766 & 3,261 & 0,3976 & - & \\
Ni-Cu/HZSM-5_10(1:1) & 356,173 & 3,240 & 0,2885 & 5,24 & 1,47 \\
\hline
\end{tabular}

$* \mathrm{a}, \mathrm{b}, \mathrm{c}=$ hasil analisa BET

$* \mathrm{~d}=$ hasil analisa EDX
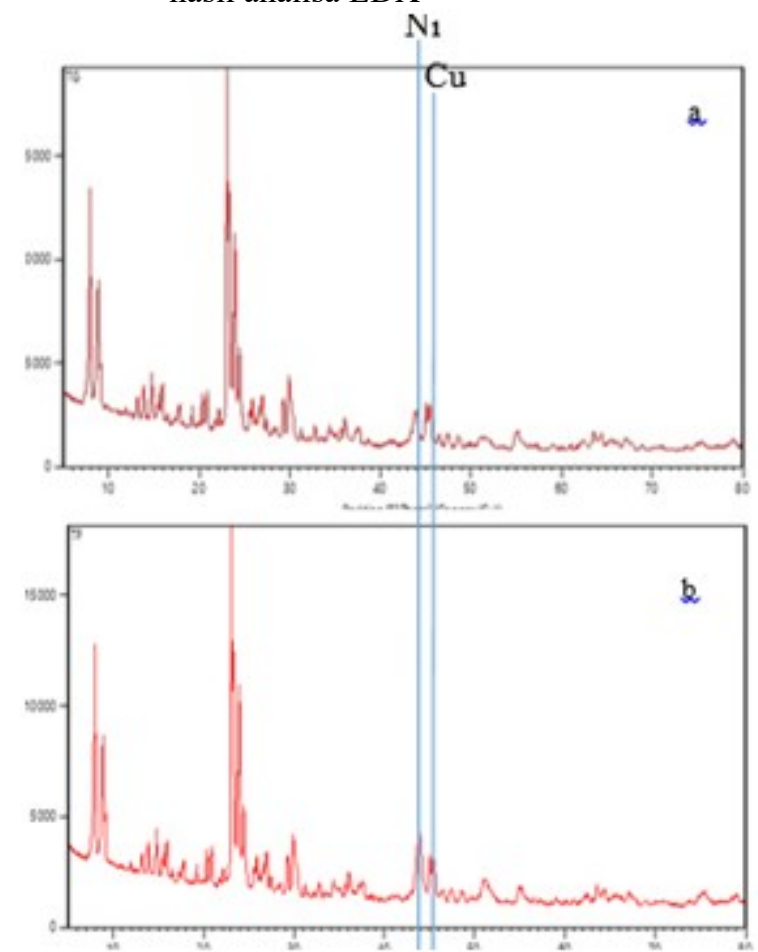

Gambar 2. Difraktogram XRD a) Ni-Cu/HZSM 10(1:1), b) $\mathrm{Ni}-\mathrm{Cu} / \mathrm{HZSM} 5(1: 1)$, c) Ni- Cu/HZSM_5(1:2), d) Ni-Cu/HZSM_5(1:1)

Penurunan luas permukaan untuk masing-masing katalis dikarenakan mikropori dari zeolite HZSM-5 terisi dengan logam. Semakin banyak logam yang ditambahkan pada permukaan padatan HZSM-5, maka akan berpengaruh terhadap menurunnya luas permukaan dari katalis tersebut. Hal ini disebabkan jumlah logam yang semakin banyak, maka akan terjadi kompetisi untuk berdifusi ke dalam mulut pori [13].Penambahan logam pada support HZSM-5 diharapkan mampu meningkatkan aktivitas dari katalis yang dihasilkan [14]. Berkurangnya luas permukaan dari katalis bukan berarti efektifitas dari katalis menjadi berkurang, tetapi justru logam akan menambah sisi aktif pada katalis yang akan mempengaruhi laju reaksi didalam katalis [15].

Fenomena pada variabel yaitu total volume pori dari katalis yang dihasilkan yaitu semakin besar loading dan rasio logam setelah impregnasi, maka total volume pori yang dihasilkan mengalami penurunan. Hal tersebut menunjukkan bahwa partikel bimetal berhasil terdispersi dan masuk ke dalam pori-pori HZSM-5. Walaupun pada variabel $\mathrm{Ni}-\mathrm{Cu} / \mathrm{HZSM}-5$ 5(1:1) volume pori mengalami kenaikan karena kelebihan beban parsial permukaan support yang menghalangi sistem berpori [15] namun hal tersebut tidak menyebabkan efektifitas dari katalis berkurang.

\section{Analisa Produk Gasoil}

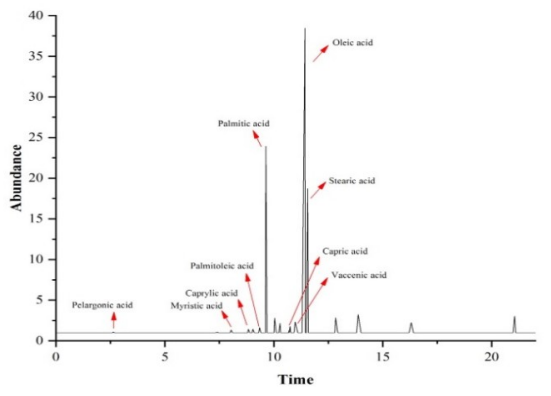

Gambar 3. Spektra GC-MS minyak bintaro

Gambar 3 Hasil analisa minyak bintaro menunjukkan bahwa asam lemak terdiri dari beberapa komponen asam lemak yaitu, asam pelargonat/asam oksalat pada waktu tinggal 2,6; asam miristat pada waktu tinggal 7,4; asam kaprilat pada waktu tinggal 8,8; asam palmitoleat pada waktu tinggal 9,3; asam palmitat pada waktu tinggal 9,610,3 ; asam kaprik pada waktu tinggal 10,7 ; asam vaccenic pada waktu tinggal 10,74 ; asam oleat pada waktu tinggal 11,4 dan 16-21; asam stearat pada waktu tinggal 11,5. 
Asam lemak terbanyak yang terkandung dalam minyak bintaro adalah oleat, palmitat, dan stearat sebanyak 39,32\%, $27,64 \%$, dan $17,73 \%$. Dimana asam lemak tersebut akan tercracking menjadi rantai hidrokarbon yang lebih pendek untuk menghasilkan produk gasoil.

Gambar 4 menunjukkan spectra GC-MS produk cair yang dihasilkan dari hydrocracking minyak bintaro menggunakan katalis Ni-Cu/HZSM-5 pada waktu tinggal 215. Hasil ini menunjukkan, terjadinya proses penghilangan atom oksigen dari asam lemak yang memiliki molekul rantai panjang menjadi molekul rantai pendek.

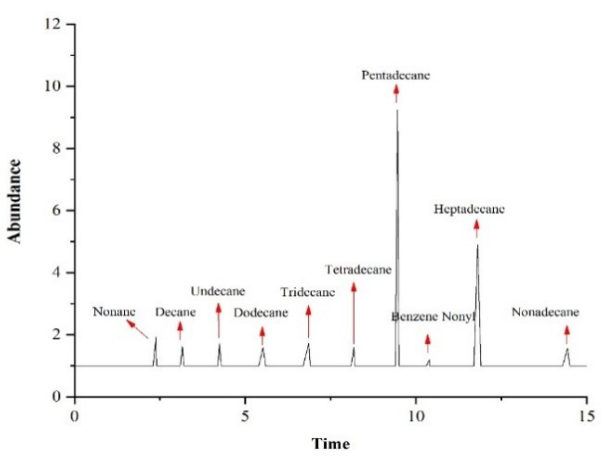

Gambar 4. Spektra GC-MS produkhydrocracking dengan menggunakan Ni-Cu/HZSM-5_10\%(1:1)

Setelah melakukan pengelompokan berdasarkan rantai hidrokarbon C14-C20 yang mana merupakan kelompok gasoil berdasarkan perhitungan persamaan 4 [17] maka didapatkan yield gasoil sebesar $82,7 \%$ dan $23,75 \%$ dengan penggunaan variabel ratio dan loading katalis Ni-Cu/HZSM-5 berturut-turut 5(1:1) dan 10(1:1).

Yield gasoil $=\frac{\text { gasoil } x \text { berat total produk cair }}{\text { berat umpan }} \times 100 \%$ (4)

Yield gasoil yang diperoleh cenderung lebih besar dibandingkan dengan proses hydrocracking menggunakan katalis HZSM-5 tanpa dilakukan impregnasi logam. Pada hydrocracking minyak kemiri sunan, minyak kelapa, dan minyak biji karet menggunakan katalis HZSM-5 diperoleh yield gasoil berturut-urut sebesar $42,7 \%, 4 \%$, dan $31,25 \%$ [18] [19].

Secara umum, katalis yang digunakan dalam proses hydrocracking minyak nabati harus terdiri dari dua sites yaitu metallic sites dan acid sites. Metallic sites diperlukan untuk reaksi hidrogenasi, dekarboksilasi, dekarbonilasi, dan reaksi hidrodeoksigenasi. Acid sites diperlukan untuk isomerisasi dan reaksi perengkahan (cracking) [21]. Oleh karena itu, menyeimbangkan antara logam dan asam merupakan faktor yang sangat penting dalam mendesain katalis untuk mengubah selektivitas, aktivitas, dan daya tahan katalis. Dalam penelitian ini komposisi loading support HZSM-5 5\% dengan rasio logam 1:1 lebih efektif menghasilkan gasoil dibandingkan dengan Ni-Cu/HZSM-5 $10 \%(1: 1)$.

Hal tersebut didukung dengan hasil penelitian terdahulu yang menggunakan beberapa jenis bimetal dalam proses hydrocracking minyak bintaro, antara lain: Ni-Co/HZSM-5; Ni-Fe/HZSM-5; serta Ni-Zn/HZSM-5 dengan 5\% dan 10\% loading menghasilkan yield gasoil berturut-urut $60 \%$ dan $42 \% ; 44,3 \%$ dan $22,4 \%$; serta $45,4 \%$ dan $27,3 \%$ [3][18].

Dari Gambar 5 menunjukkan komponen hidrokarbon dari produk gasoil yang dihasilkan. Trigliserida pada minyak bintaro terpecah menjadi komponen hidrokarbon dengan rantai yang lebih pendek. Rasio n-alkana dengan jumlah atom karbon ganjil (seperti n-C15) dengan n-alkana bilangan atom karbon genap (seperti n-C16) dapat bertindak sebagai indikator untuk mengevaluasi jalur reaksi hydrocracking [18].

Terlihat bahwa rantai pentadekan (C15) dan heptadekan (C17) atau rantai hidrokarbon ganjil mendominasi hasil reaksi pada kedua variabel loading.

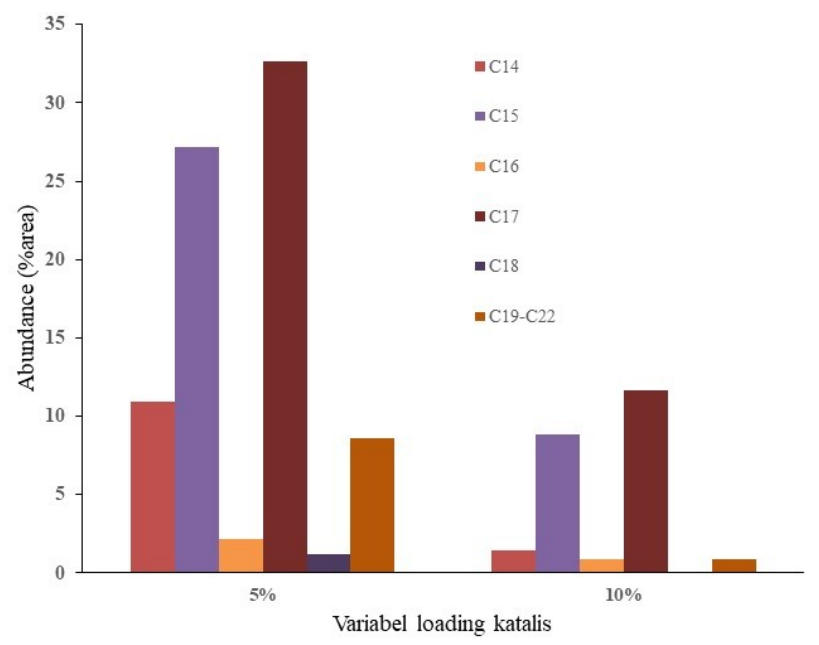

Gambar 5. Rantai hidrokarbon produk gasoil dari hydrocracking minyak bintaro

Banyaknya rantai hidrokarbon ganjil atau rasio C15/C16 dan C17/C18 menunjukkan bahwa reaksi dekarbonilasi dan dekarboksilasi (HDC) menjadi reaksi utama pada proses hydrocracking minyak bintaro. Hasil samping dari reaksi tersebut yaitu gas $\mathrm{CO}$ dan $\mathrm{CO}_{2}$.

Di sisi lain dekarboksilasi dan dekarbonilasi merupakan reaksi endotermis sehingga membutuhkan temperatur yang lebih tinggi. Sedangkan hidrodeoksigenasi merupakan reaksi eksotermis [23]. Hal tersebut menyebabkan dekarbonilasi dan dekarboksilasi menjadi rute reaksi dominan pada proses hydrocracking dengan temperatur tinggi. Reaksi ini juga menyebabkan penggunaan konsumsi hidrogen dapat dikurangi, sehingga pada akhirnya, kelayakan ekonomi proses produksi biofuel akan tercapai [6].

\section{KESIMPULAN}

Preparasi katalis Ni-Cu/HZSM-5 menggunakan metode incipient wetness impregnation telah berhasil dilakukan sebagaimana yang ditunjukkan oleh hasil analisa karakteristik katalis yaitu BET, EDX, dan XRD. Penambahan bimetal Ni-Cu pada HZSM-5 sangat efektif dalam meningkatkan aktivitas katalis untuk memproduksi gasoil. Dilihat dari variabel katalis yang terkecil $(5 \% ; 1: 1)$ menghasilkan yield gasoil sebesar 82.7\%. Reaksi hidrodekarbonilasi atau hidrodekarboksilasi (HDC) merupakan reaksi utama pada proses hydrocracking minyak bintaro. 


\section{UCAPAN TERIMA KASIH}

Penelitian ini merupakan bagian dari penelitian yang didanai oleh Kementrian Riset Teknologi dan Pendidikan Tinggi melalui Program Magister tahun 2019-2020. Karenanya diucapkan terima kasih.

\section{DAFTAR PUSTAKA}

[1] Kementerian Pertanian, Outlook Komoditas Pertanian Perkebunan, Pusat Data dan Informasi Pertanian Kementerian Pertanian, Jakarta, 2010.

[2] Kementerian ESDM, Kebijakan Pengembangan Energi Baru Terbarukan dan Konservasi Energi (EBTKE), Departemen Energi dan Sumber Daya Mineral, Jakarta, 2006.

[3] M.A. Muttaqii, Hydrocracking Minyak Nabati Menjadi Biofuel Menggunakan Katalis Bimetal Berbasis Ni/HZSM-5, Teknik Kimia ITS, Surabaya, 2016.

[4] D. Endriana, Sintesis Biodiesel (Metil ester) dari Minyak Biji Bintaro (Cerbera Odollam Gaertn) hasil ekstraksi, Kimia MIPA-UI, Universitas Indonesia, Jakarta, 2007.

[5] G.W. Huber, P. O'Connor, dan A. Corma, Processing biomass in conventional oil refineries: production of high quality diesel by hydrotreating vegetable oils in heavy vacuum oil mixtures, Applied Catalysts A, vol. 329, pp. 120-129, 207.

[6] E. Rosyadi, Konversi Minyak Nabati menjadi Green Diesel dan Green Gasoline dengan Proses Hydrocracking dan Hydrotreating pada Katalis NiMo/A12O3, Instutut Teknologi Sepuluh November, Surabaya, 2012.

[7] R. Sotelo-Boyás, F. Trejo-Zárraga, F.J HernándezLoyo, Hydroconversion of Triglycerides into Green Liquid Fuelsl, Ch. 8, 2012.

[8] C. Barrón, J. A. Melo-Bandaa, E. J. M. Dominguez, M. E. Hernández, R. R. Silva, T. A. I. Reyes, M.M.A Meraz, Catalytic hydrocracking of vegetable oil for agrofuels production using $\mathrm{Ni}-\mathrm{Mo}, \mathrm{Ni}-\mathrm{W}, \mathrm{Pt}$ and TFA catalysts supported on SBA-15, Catalysis Today, vol. 166 no. 1, pp. 102-110, 2011.

[9] S. Vichaphund, D. Aht-ong, V. Sricharoenchaikul, Catalytic upgrading pyrolysis vapors of Jatropha waste using metal promoted ZSM-5 catalysts, Renewable Energy, vol. 65, pp. 70-77, 2014.

[10] S. Sartipi, M. Alberts, M. J. Meijerink, T. C. Keller, J. Pérez-Ramírez, J. Gascon, and F. Kapteijn, Towards Liquid Fuels from Biosyngas: Effect of Zeolite Structure in Hierarchical-Zeolite-Supported Cobalt Catalysts, ChemSusChem, vol. 6, no. 9, pp. 16461650, 2013.

[11] G. W. Huber, P. O’Connor, dan A. Corma, Processing biomass in conventional oil refineries: production of high quality diesel by hydrotreating vegetable oils in heavy vacuum oil mixtures, Applied Catalysts A, vol. 329, pp. 120-129, 2007.
[12] S. Vichaphund, D. Aht-ong, V. Sricharoenchaikul, Production of aromatic compounds from catalytic fast pyrolysis of Jatropha residues using metal/HZSM-5 prepared by ion-exchange and impregnation methods, Renewable Energy, vol. 79, pp. 28-37, 2015.

[13] E. Astuti, Pengaruh Konsentrasi Katalisator dan Rasio Bahan terhadap Kualitas Biodiesel dari Minyak Kelapa, Jurnal Rekayasa Proses, Fakultas Teknik Universitas Gajah Maja, Yogyakarta, 2012.

[14] H. Li, P. Yu, B. Shen, Biofuel potential production from cottonseed oil: a comparison of non-catalytic and catalytic pyrolysis on fixed-fluidized bed reactor, Fuel Process Technology, vol. 90, pp. 1087-1092, 2009.

[15] H. S. Fogler, Elements of Chemical Reaction Engineering, 3rd edition, Prentice Hall International Series in the Physical and Chemical Engineering Series, 1999.

[16] H. V. Bekkum, E. M. Flanigen, P. A. Jacobs, J. C. Jansen, Introduction to Zeolite Science and Practice, Elsivier, Oxford, 2007.

[17] Al-Muttaqii, M., Kurniawansyah, F., Prajitno, D. H., Roesyadi, A., "Bio-kerosene and Bio-gasoil from Coconut Oils via Hydrocracking Process over Ni-Fe/HZSM-5 Catalyst", Bulletin of Chemical Reaction Engineering \& Catalysis, 14.2: 309, 2019.

[18] L. Marlinda, M. Al-Muttaqii, A. Roesyadi, Formation of hydrocarbon compounds during the hydrocracking of non-edible vegetable oils with cobalt-nickel supported on hierarchical HZSM-5 catalyst, IOP Conference Series: Earth and Environmental Science, vol. 67, no. 1, IOP Publishing, 2017.

[19] P. Yotsomnuk, W. Skolpap, Biofuel Production from Waste Virgin Coconut oil by Hydrocracking over HZSM-5 Zeolite, International Journal of Advances in Science Engineering and Technology, vol. 5, pp. 60-63, 2017.

[20] N. Kyungsu, C. Minkee, R. Ryong, Recent Advances in the synthesis of Hierarchically nanoporous zeolites, Microporous and Mesoporous, Materias, vol. 166, pp. 3-19, 2013.

[21] B. Al Alwan, Biofuels Production Via Catalytic Hydrocracking of Corn Oil And Hydrothermal Decarboxylation Of Oleic Acid Over Transition Metal Carbides Supported On Al-Sba-15, Ph.D. Disertation, Wayne State, University, Detroit, Michigan, 2014.

[22] L. Chen, H. Li, J. Fu, C. Miao, Lv. Pengmei, Z. Yuan, Catalytic hydroprocessing of fatty acid methyl esters to renewable alkane fuels over Ni/HZSM-5 catalyst, Catalyst Today, vol. 259, pp. 266-276, 2016. 